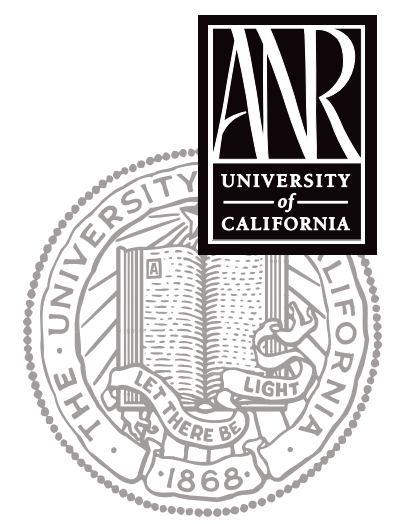

UNIVERSITY OF CALIFORNIA

Division of Agriculture and Natural Resources http://anrcatalog.ucdavis.edu

\title{
Raising Dairy Goat Kids
}

JOLENE BERG, Department of Animal Science, UC Davis; PETER ROBINSON, UC Cooperative Extension Specialist, Department of Animal Science, UC Davis; and DEBORAH GIRAUD, UCCE Farm Advisor, Humboldt County.

Anyone who has worked with dairy goat kids knows that raising them, especially on a commercial scale, can be a challenging yet gratifying endeavor. Kids are the replacement animals that keep a herd at optimum production. It takes a lot of work and careful attention to produce a hard-working dairy goat from one of these bouncing babies. In this publication we have taken special care to include information compiled from other published literature as well as practical advice from experienced commercial herders who follow these methods.

This is not meant to be a complete reference on raising kids on a commercial scale, but rather a sharing of successful practices used by commercial producers. Also, if you are looking into starting or acquiring a commercial-scale dairy goat operation, this publication will give you a general sense of the practices involved so you can make a more educated decision as to whether this is the right business for you. For more detailed information, we encourage you to consult the publications listed under References and Resources and to visit as many commercial goat operations as you can before you actually start your own operation.

Some goat breeders are looking into the idea of raising dairy doe replacement stock for sale to commercial milk producers as a separate business. Good management practices are essential for success in this type of enterprise.

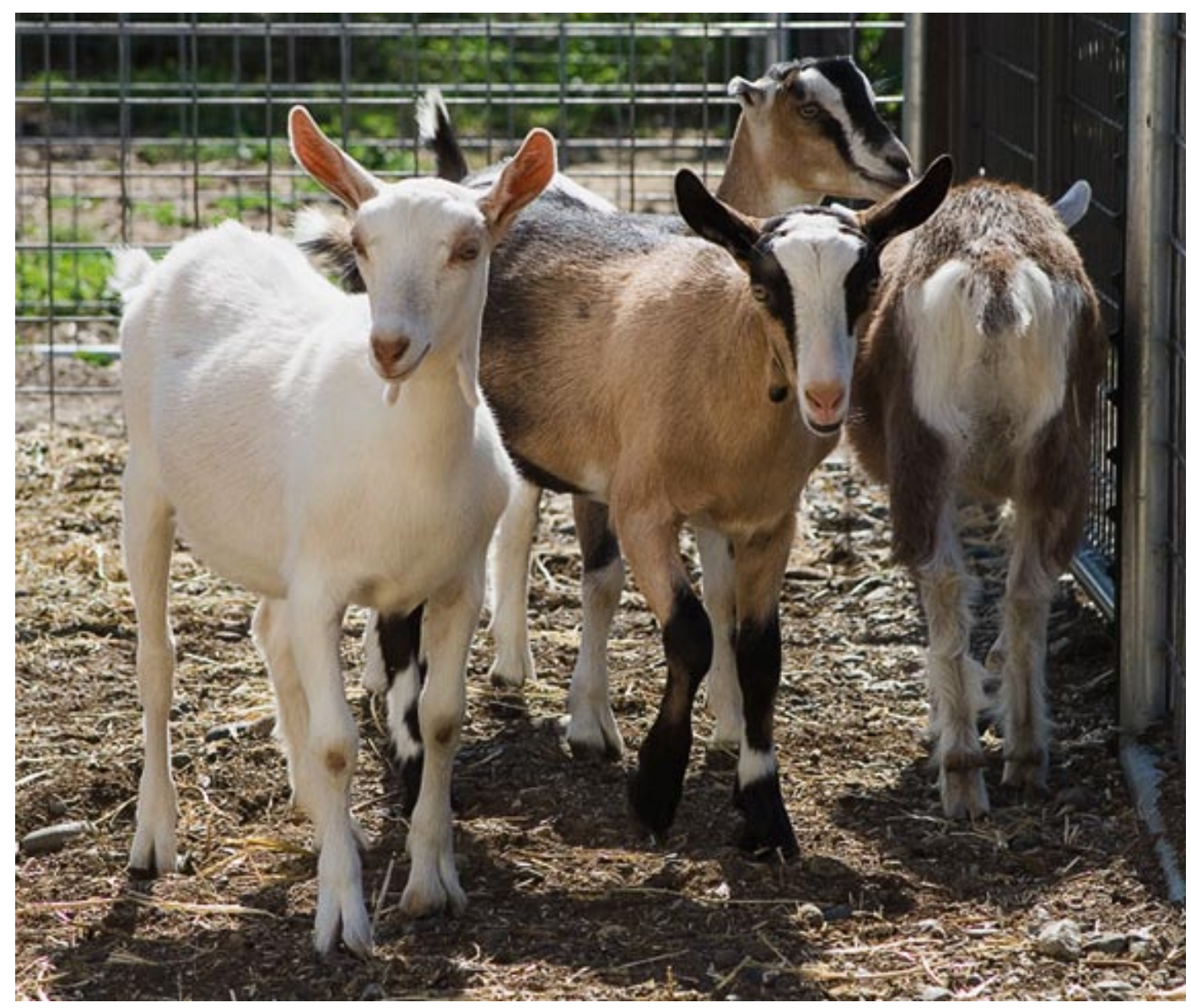




\section{DIGESTIVE ANATOMY OF THE GOAT}

Adults. Goats are ruminants and, as such, have a digestive system that is defined as pre-gastric fermentation. This means that ingested feeds are first fermented by bacteria in the rumen before they pass to the small intestine to be digested by enzymes. The forestomachs comprise the rumen and a smaller compartment attached to it called the reticulum (correctly referred to as the reticulo-rumen but often simply as the rumen) into which the ingested feed first enters, as well as the omasum, into which only some feed enters on its way through the omasal canal from the rumen to the abomasum. The abomasum is the fourth (or final) stomach and is equivalent to the stomach in a monogastric animal such as a human.

The rumen is the largest compartment and contains billions of bacteria and protozoa that digest carbohydrates such as fiber and starch as well as proteins and, to a very limited extent, fats and minerals. These bacteria produce compounds called volatile fatty acids (VFA), which are absorbed by the rumen to become an important source of energy to the goat. The bacteria also create microbial biomass, largely in the form of protein and digestible carbohydrate, which passes out of the rumen to be digested, along with non-fiber feed nutrients that were not digested in the rumen. This microbial biomass and the feed nutrients that escape the rumen, together with the VFA absorbed by the rumen, provide the nutrients required by the goat to grow and produce milk. The rumen must be fully functional to maintain animal performance.

Goats are also defined as browsers, ruminants that select their diet from a range of available feedstuffs. They are very good at selecting the most nutritious portions of grasses, hays, shrubs, and trees to maintain rumen function as well as digestion of nutrients. Goats are generally intolerant of diets low in digestible nutrients; they are able to select the more nutritious parts of even those feeds and browse plants that have a low overall nutritional value, but forcing them to consume a diet of low digestibility-for example, by grinding the feeds and mixing them-can prove fatal.

Kids. Goat kids are not ruminants at birth. For the first 7 to 14 days of life a kid's forestomachs (with the exception of the abomasum) are poorly developed and it must rely on milk or milk replacers for nutrients. As the kid begins to eat dry feeds, the rumen and reticulum begin to develop: they establish a microbial population and increase in size. Kids must be fully functional ruminants before they are weaned, and pre-weaning management is designed to ensure that they are.

\section{FEED NUTRIENTS}

Nutrients are generally divided into those whose value can be determined analytically in a laboratory and those whose value must be estimated. Our discussion here will only outline the key nutrients in goat nutrition. For a more complete discussion of these nutrients as well as goat and kid nutritional requirements, you can refer to the National Research Council's 1981 publication, Nutrient Requirements of Goats, which is the most recent NRC publication on this subject

Protein. A feed's protein content is generally estimated by multiplying the total nitrogen $(\mathrm{N})$ content of the feed by 6.25 (this method assumes that the only N present in the feed is in protein molecules and that the proteins are about $16 \% \mathrm{~N}$ ). Protein is one of the most important nutrients, as it supports bacterial growth in the rumen (as ruminally degraded protein [RDP]) and muscle growth in the goat, and serves as a source of energy as ruminally undegraded protein (UDP), most of which is digested in the small intestine, although some is excreted in feces.

Carbohydrates. The two main groups that account for most carbohydrates are the structural carbohydrates (i.e., fiber, generally assayed as neutral detergent fiber 
[NDF]) and the non-structural carbohydrates (primarily starches and sugars). NDF is digestible only in the rumen by bacteria that mostly create volatile fatty acids (VFA). Any NDF that is not digested in the rumen pass in feces. In contrast, starches and sugars can be fermented in the rumen to produce VFA, but any of these that are not digested in the rumen can be digested by enzymes in the goat's small intestine.

Fats. Fats are poorly digested in the rumen. If fed at high levels, fats can reduce the activity of rumen bacteria, thereby reducing rumen function and feed intake. Fats that escape the rumen can be digested in the intestine and are a good source of energy for the goat.

Minerals. Goats require a number of minerals to support their body functions. These nutrients are generally divided into macro-minerals (such as calcium and phosphorous) that are required at relatively high levels or micro-minerals (such as zinc and copper) that are required at relatively low levels.

Mineral supplements should be an essential component of kid rations, as they help prevent metabolic diseases. A wide variety of trace mineral supplements are available commercially, and though most are not designed specifically for goats they will often do just fine. For example, at the UC Davis Dairy Goat Facility kids are given a trace mineral supplement developed for beef cattle. One caution, however: mineral supplements designed for sheep may be too low in copper for goats, as sheep are much more susceptible to copper toxicity than goats are.

Vitamins. The vitamins a goat needs can be divided into two groups. Those that are fat soluble (e.g., vitamins A, D, and E) must be provided in the diet as the animal cannot create them. Those that are water soluble (e.g., the B complex vitamins) are created by bacteria in the goat's rumen and need not be supplied in the diet.

Energy. The usable energy level of a feed cannot be measured in a laboratory, so you have to estimate it based upon those nutrients that can be analyzed. Energy levels of feeds and animal requirements for energy are most often expressed as total digestible nutrients (TDN, an estimate of the percentage of the feed that is digested), digestible energy (DE, an estimate of the proportion of the gross [i.e., total] energy in the feed that is digestible), metabolizable energy ( $\mathrm{ME}$, an estimate of the proportion of DE that can be used by the animal), and net energy (NE, an estimate of the proportion of ME that can be used for productive purposes). In some ways, NE is the easiest to understand, as it is simply the sum of the gross energy content of the milk produced, any body weight gain, and the heat that the goat produces in maintaining its body.

Water. All goats require water in order to live, grow and produce milk, but water is often overlooked when considering a goat's nutritional needs. While water is usually made available to kids, its cleanliness and freshness are often not a priority. This may seem like a minor point, but, as in their feed preferences, goats are rather picky. In the absence of any other option, goats will drink whatever water is available. Feed intake will increase dramatically, however, if you make fresh, clean water available. This may be the best argument in favor of using automatic waterers. A variety of designs are available through livestock equipment suppliers, although you must take care to make sure that your goats know how to use them. Managers of the UC Davis Goat Facility consider automatic waterers to be the ideal method for offering a continuous supply of clean, fresh water. Supply pipes for the automatic water system should be kept out of direct sunlight to avoid heating of the water, which can promote algae growth.

\section{PRENATAL MANAGEMENT}

Effective care of the newborn kid begins before birth with the care of the pregnant doe. Adequate nutrition, without promoting obesity, during pregnancy is essential to the birth of a strong, healthy kid. If you choose to use a vaccination program such as that 
against tetanus toxoid and Clostridium C and D, vaccinating 4 to 6 weeks before parturition can boost the antibodies passed to kids through the colostrum.

Keep a close watch on does that are due to kid: this is important in preventing unnecessary losses from dystocia (difficulties during birthing). Most herd managers also separate kids from their mother shortly after birth, and this has several benefits that more than make up for the extra time commitment it requires. First, it decreases the incidence of diseases such as caprine arthritic encephalitis (CAE), Chlamydia, and other viruses that can be passed from doe to kid. Second, it allows the majority of the doe's milk to be sold commercially for processing and human consumption. Third, you can more directly monitor the feed intake and health of the kid. And fourth, the kids become used to human interaction and are less likely to view handling by humans as a threat.

\section{MANAGEMENT AFTER BIRTH}

Immediately after birth, the newborn's navel should be dipped with a disinfectant. This is important as any remaining umbilicus can provide a direct route for pathogens from the environment to enter the newborn's system. A 7\% tincture of iodine works well for this purpose as its alcohol base also helps dry the cord quickly. You can also use Betadine (povidone-iodine) or Nolvasan (chlorhexidine diacetate), but neither has the added drying effect of tincture of iodine, which is an important effect of navel dipping. Another important safety precaution is to provide newborn kids with a clean, dry, and draft-free environment. This will help protect the kids from pathogens, bacteria, and parasites that may have been shed by older animals.

The area in which the newborn kids are kept should be easy to sanitize and clean thoroughly between groups. Experience at the UC Davis Dairy Goat Facility is that clean straw works best for bedding, as it creates a deep soft bed for kids to snuggle up in. This is preferable to other beddings such as wood shavings or sand, as these materials have smaller particles that tend to stick to the newborn's wet hair. However you house your kids, though, cleanliness must be a priority at all times. Soiled bedding creates a medium for bacteria and other pathogens that can infect the kids. It can also create fly problems that can result in the spread of infectious ailments such as pinkeye.

If there is a disease outbreak and the kid housing area requires disinfection, you can separate the kids in a clean and isolated space for a short time by using large cardboard boxes (such as those obtained from an appliance store) with a piece of tarp taped to the bottom to prevent leakage. This method only works for 1 to 2 litters each, depending on the size of the box, but it is a good way to keep the younger kids from being exposed to the older ones, and you can easily dispose of the box after no more than 7 days' use to prevent transfer of diseases among kids.

While you can use heat lamps for warmth in cool weather, keep in mind that these can also be extremely hazardous. Use them according to manufacturer instructions and take care to hang them high enough to keep them out of the reach of curious kids.

\section{COLOSTRUM MANAGEMENT}

Another extremely important management practice is getting kids their first colostrum. Colostrum, the doe's first milk after parturition, is usually much thicker and more yellowish than subsequent milkings. The quality of a doe's colostrum is affected by many factors, such as nutrition during pregnancy (especially close to parturition), what pathogens she has been exposed to, what vaccinations she has received, the season of the year, the doe's age (colostrum of older does tends to be higher in antibodies because they have been exposed to more environmental pathogens), and the amount of colos- 
trum that she produces (in general, colostrum quality goes down as the amount produced increases, but this is not always the case).

The first milking is always the highest-quality colostrum as it has the most antibodies. Sometimes the second-milking colostrum is also of good quality, particularly with older does, and can be used. A colostrometer, which measures the quality of the colostrum, can be a helpful aid and can usually be purchased from a dairy supply store or catalog. This is especially useful when you are mixing colostrum from different does. For example, you can blend a low-quality colostrum with a high-quality colostrum to make a usable mix and not waste the lower-quality material. To facilitate the mixing of colostrum from different does, whether you use a colostrometer or assess colostrum quality based on factors such as the age of the doe, it is best to keep track of the origin of each container of colostrum.

Not everyone favors the mixing of raw colostrum, as it can also mix causative agents of diseases that may only be present in the colostrum of a few does. You can heat-treat colostrum (discussed below) to inactivate the disease-causing agents.

Colostrum provides the kid with an extremely high-nutrient diet that stimulates both its metabolism and its digestive activities. Colostrum tends to be much higher in protein, vitamins, and minerals than regular milk, and so gives the kid a jump-start at a time when it has low amounts of these essential nutrients. When it is first born, the kid has very little immunity to the pathogens it will encounter in the environment. Instead, it depends on passive immunity from the antibodies received in colostrum to fight diseases. At the UC Davis Dairy Goat Facility, all colostrum is heat-treated before being fed to the kids in order to minimize the instance of CAE in the herd as well as to help control pathogens that may have contaminated the colostrum during handling. Three of six commercial dairies surveyed also held this to be an important practice (see Appendix Table). Note that heat-treating should not be confused with pasteurization, as pasteurization is the process of heating milk to $165^{\circ} \mathrm{F}\left(73.9^{\circ} \mathrm{C}\right)$ for at least 5 seconds to kill bacteria. At temperatures above about $135^{\circ} \mathrm{F}\left(57.2^{\circ} \mathrm{C}\right)$, colostrum begins to cook and solidify and undergoes a sharp loss in its nutritional and antibody value to the kid. For this reason heat-treated colostrum is only heated to $135^{\circ} \mathrm{F}\left(57.2^{\circ} \mathrm{C}\right)$ and held at that temperature for 60 minutes to effectively kill all pathogenic bacteria. While this process is more labor intensive than feeding the kids on raw colostrum, it minimizes the risk of disease.

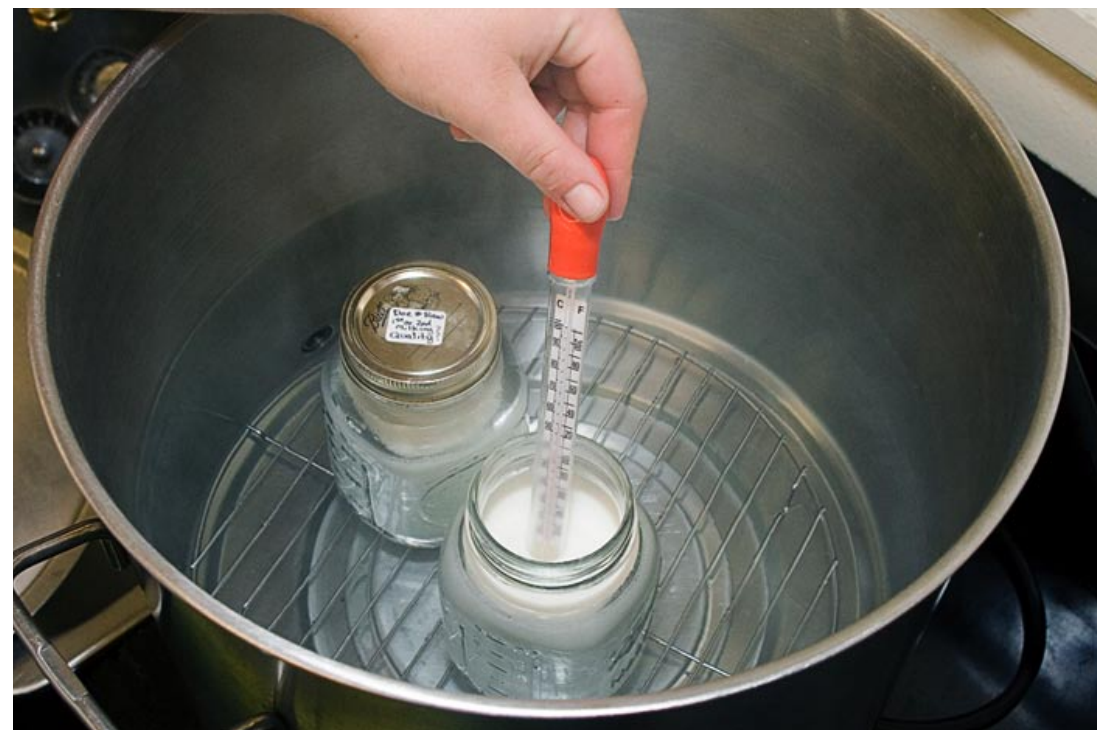

A hot water bath prevents scorching as it maintains an even temperature for the 60-minute heat-treatment period for colostrum.
Several commercial devices are available from livestock equipment suppliers to heat-treat colostrum. Heat treatment by "cooking" on a stove top or other direct heat source may scorch the colostrum; heating on the stove top in a double boiler or hot water bath, however, is widely used with good results.

Some surveyed producers felt that heat-treating was not sufficiently cost- or time-effective to justify its practice or that heat-treating caused loss of some essential nutrients and antibodies. While raw colostrum can sometimes be fed with good results, great care must be taken to prevent contamination with pathogenic bacteria during handling. Feeding newborn kids on raw colostrum does not help 
prevent CAE infection, which is passed from a positive doe to the kid through milk. If you feed kids on raw colostrum, you need to test your does regularly to identify those that are CAE positive so you will be able to avoid feeding their raw colostrum and milk to kids. When they know a doe is CAE-free, producers can leave a kid to nurse for one or two days before separation and bottle feeding, to get the colostrum. This method may save time, but there is always a chance that the producer will be mistaken about the doe, in which case this practice would greatly increase the risk of passing CAE to kids. Aside from any CAE risk, though, when you leave a newborn kid to nurse you have no way to monitor the quality or quantity of colostrum that it receives. Under some circumstances it can even take more time to do things this way, for instance if many does kid at the same time and you have not kept track of which kid goes with which mother, or if a doe freshens with mastitis, in which case a direct-nursing kid may not receive any colostrum at all. Sometimes kids are harder to bottle train after having nursed their dam, as they may see the bottle and the human who presents it as new and frightening stimuli.

Another option is to use powdered colostrum, which is becoming more widely available and can be used when you are short on fresh colostrum. The actual efficacy of powdered colostrum is not clear, however. One drawback is that when you use colostrum that does not come from your own herd, you may not be giving your kids antibodies to the pathogens that your does have been exposed to in your environment. These are the same pathogens that your kids will likely encounter.

An additional consideration is when to feed colostrum to kids and how much to feed them. Antibodies are relatively large molecules made primarily of protein. When the kid is born, its digestive tract wall is not fully mature and so allows these large antibodies to pass through to the bloodstream. Maturation of the tract wall, or gut closure, occurs very soon after birth and is virtually complete within 24 hours of birth. As this maturation process progresses, the gut absorbs fewer and fewer antibodies, to the point that it can absorb no antibodies at all about 24 hours after birth. The kid will also begin to produce its own digestive enzymes about 6 hours after birth, and these start to digest the antibodies into smaller protein components, destroying their disease-preventive functionality before they can be absorbed into the blood. For all of these reasons, rapid, early ingestion of colostrum is critical to antibody absorption by the kid.

At the UC Davis Dairy Goat Facility, kids receive 8 oz. of colostrum within 12 hours of birth. This sometimes requires that the kids be given a few small feedings, beginning with attempts directly after birth. If a kid is weak or stubborn and does not accept bottle feeding after a few unsuccessful attempts, you can use a feeding tube to ensure that the kid receives an adequate amount of colostrum before gut closure. Feeding tubes are available from most livestock supply catalogs, but they can be hard for an inexperienced person to insert properly into the abomasum. A kid that has received the recommended amount of colostrum is much more active and alert and, usually, increasingly easy to feed.

How long you feed your kids colostrum is also a significant factor to their health. Even though gut closure means that kids cannot absorb antibodies after about 24 hours of life, they still utilize the nutrients in colostrum. Some of the producers we surveyed continued to feed colostrum for up to 3 days after birth, as they observed increased early growth and development in kids. As the kid's immune system is affected by its nutritional status, feeding colostrum after 24 hours of life helps kids stay healthy, even if the effect is less direct after this time. If you follow this practice, make sure to monitor your supply of colostrum to ensure there is enough for every kid to receive the recommended amount of good quality colostrum.

Clearly there are a number of views as to how much colostrum a kid should get and how and when it should get it. Whichever practice you choose, keep in mind that 


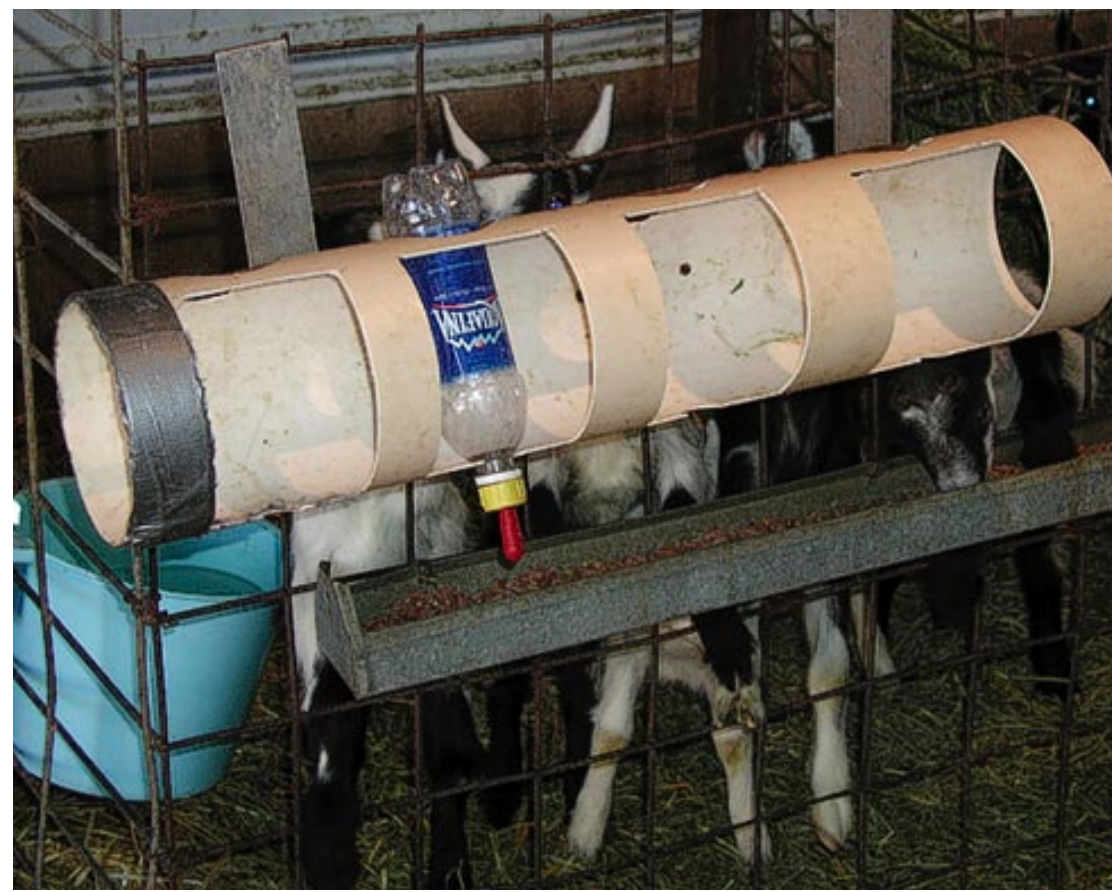

A bottle holder made from PVC pipe can be built to hold as many bottles as you like. You can easily see the contents of the bottles, snap them in and out, and monitor the kids' rate of consumption. The feeder must be kept clean at all times (this photo demonstrates an unacceptable level of cleanliness). The nipples normally point into the goat pen; the holder is reversed for this photograph to make its design easier to see. all of the surveyed producers believed feeding colostrum to be an essential element in minimizing early mortality in their kids.

\section{FEEDING: BIRTH TO WEANING}

After the initial period of feeding colostrum, most dairies use a commercial milk replacer to feed kids. This allows the dairy to sell or process the milk produced by the does for revenue. Using milk replacer saves the time and energy that would be required for pasteurizing fluid milk and avoids the potential for contamination of natural milk in handling or during transportation. Some dairies supplement the milk replacer with, or use only, fluid goat or cow milk. This method can sometimes be cheaper than buying commercial milk replacer, depending on price and availability, but it may introduce disease from other herds. Take special care to ensure that there is a steady supply from the source you choose to use, since changing a kid's diet can cause scours (i.e., runny feces and dehydration). If you must change to a new milk source, do so gradually by mixing milks for a few days.

Milk replacers that are fed to kids are either kid replacers, lamb replacers, or calf replacers. There are many brands. Some powders are more soluble than others, the prices vary considerably, and some can be bought in a medicated form for prevention of coccidiosis. As there are pros and cons to each choice, you should consult a veterinarian and experienced kid producers for advice on which is best for your operation.

Kids have a natural instinct to nurse, and feeding by bottle capitalizes on this characteristic. Although feeding with a pan may make clean-up easier and be less labor intensive, it usually takes more time and effort to teach the kid to eat this way. Feeding by bottle also allows you to monitor the kid's feed intake at this critical time of early life. Kids that are not drinking a sufficient amount of milk will be immediately identified, allowing you to take quick remedial action and prevent stunted growth at an early age. Some producers prefer to keep the kids on the bottle until weaning to solid food to make it easier to monitor their consumption.

It is common practice to feed newborn and young kids from a bottle such as a plastic soda bottle. Bottles specifically designed for feeding milk to kids are available through livestock equipment suppliers and have the benefit that, unlike single-use soda bottles, they are made of a plastic that will not degrade so easily with time.

If you using plastic soda bottles or similar bottles, make sure to replace them frequently as most are not designed for repeated use. Check the integrity of the bottles' inner surfaces carefully if cleaning chemicals are repeatedly used to sanitize them. You can make a simple bottle holder from a piece of PVC pipe hung on the pen. Bottles are snapped into the holes in the holder. One producer feeds 100 kids this way, two pens at a time, and likes how clean she can keep the bottles.

Most producers use a lamb-bar system consisting of several nipples used to feed multiple kids from a single milk supply. 
The typical system consists of a large plastic bucket with nipples pulled through holes around the top. Connected to the back of each nipple is a rubber tube that goes to the bottom of the bucket to serve as a drinking straw. These tubes are easy to clean with an pipe cleaner of the appropriate size, which you can purchase from a hardware store. The lamb-bar feeder can easily be completely dismantled and thoroughly cleaned. Don't neglect this chore, however, as milk left in the tubes will quickly spoil. The

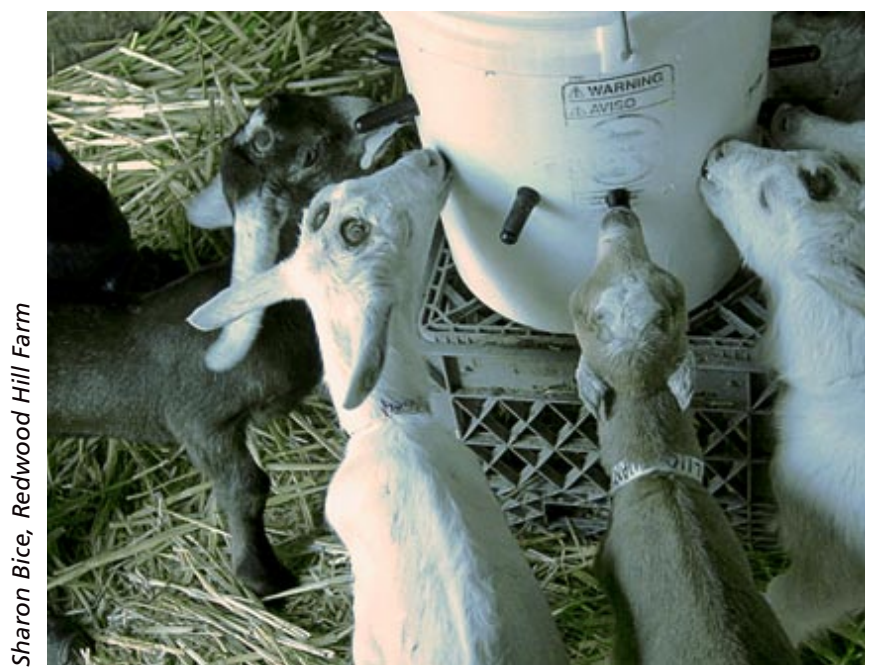

The lamb-bar; standard industry practice.
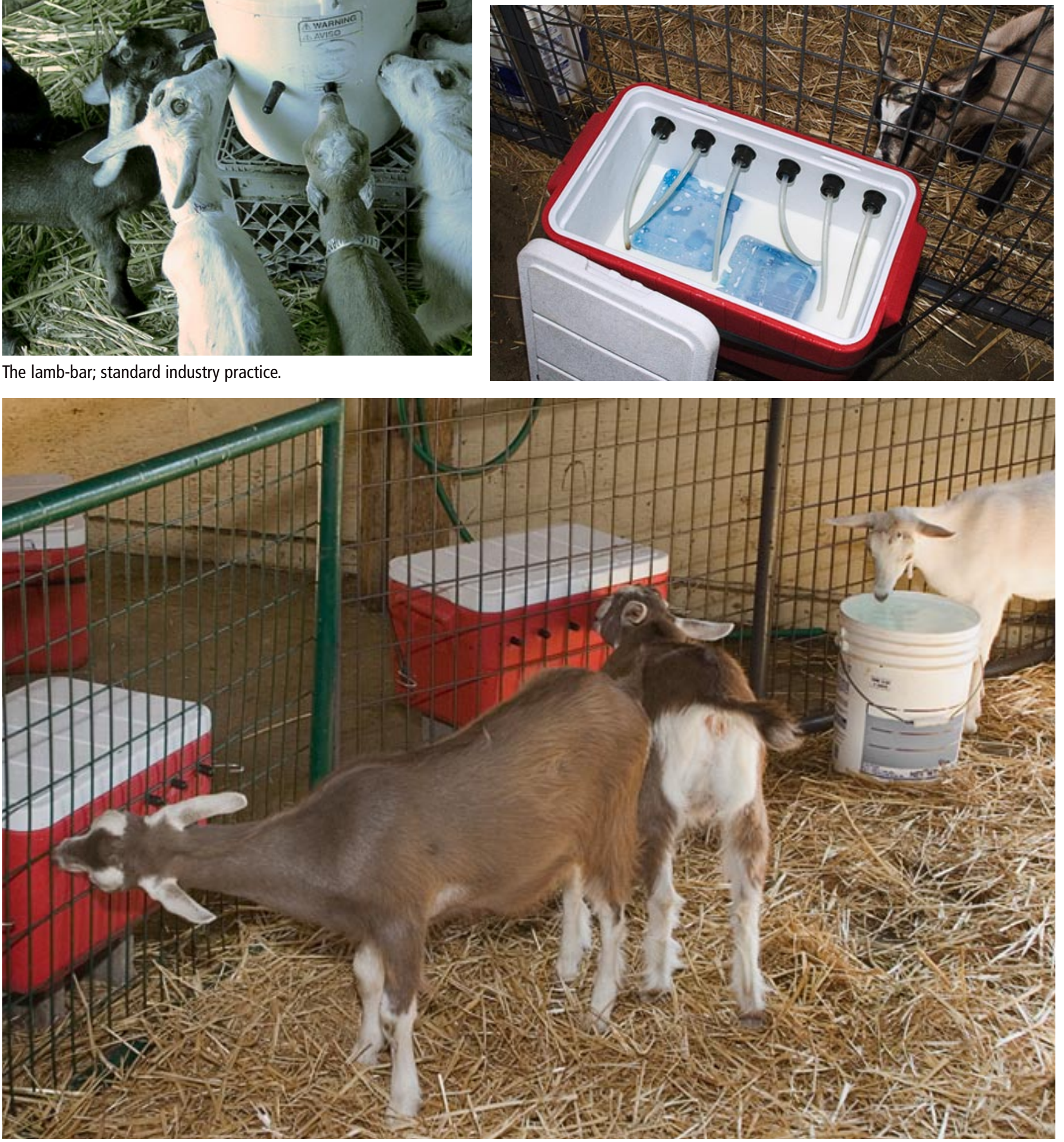

Cooler lamb-bars; the milk is kept cool all day and the kids can self-feed. 


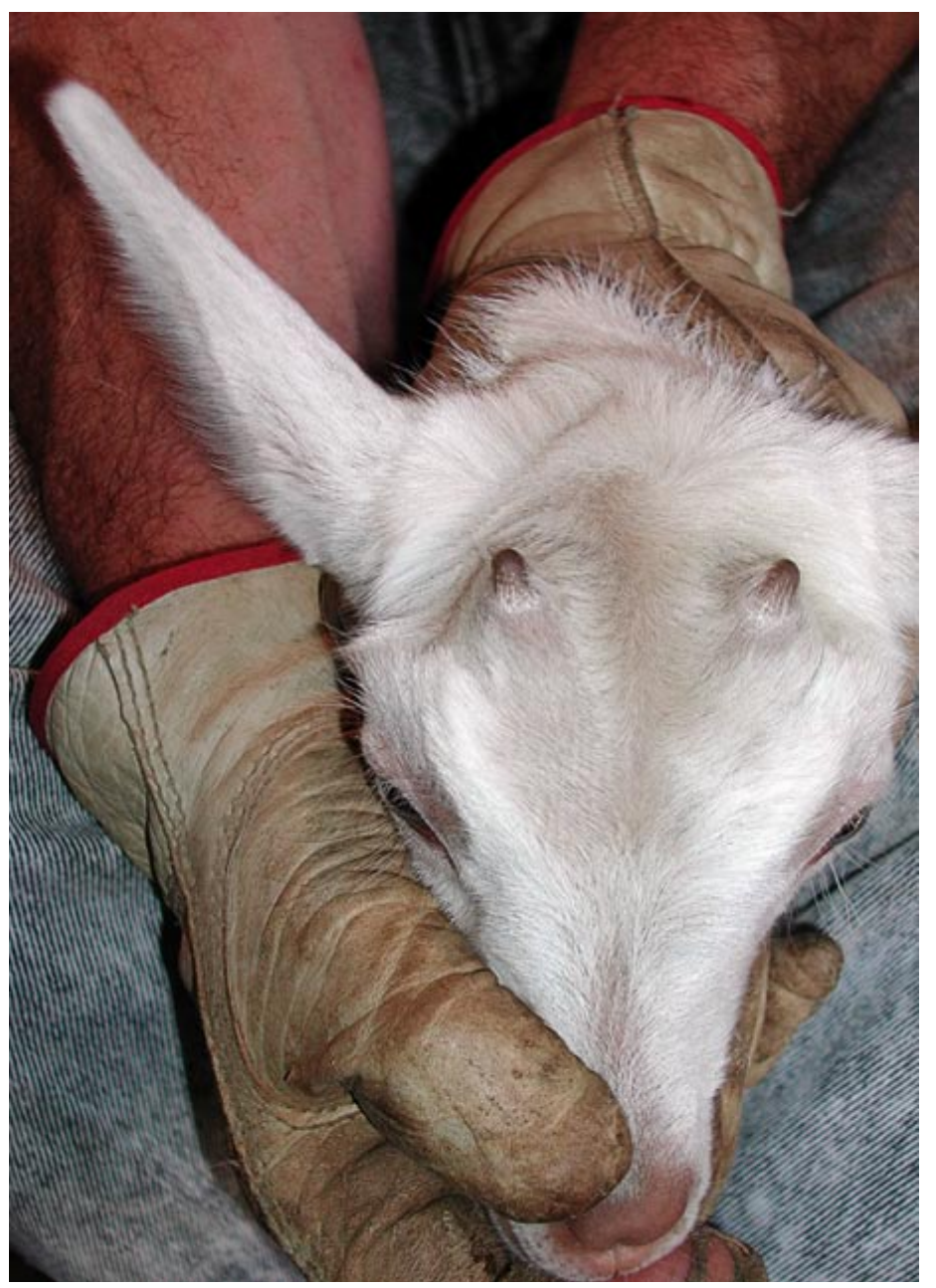

This kid's horn buds are too large and should have been removed sooner with a disbudding iron to avoid scurs (horn regrowth). feeder should also have a lid to keep flies and debris from getting into the milk. At the UC Davis Dairy Goat Facility, modified recreational coolers with an ice pack are used to keep the milk cool throughout the day, but this may not be cost-effective for a larger dairy. This method saves time as the coolers are cleaned and filled once a day and more milk can be added at night if it is needed. The kids are able to self-regulate their milk supply and drink as if they were nursing, a few ounces many times a day.

\section{DISBUDDING}

Disbudding is the removal of the horn buds of young goats and is a common management practice on most commercial dairies. This practice, although it causes the kids some short-term pain, has many benefits to the goats and the people who handle them. While horns are useful for goats in the wild, they are a management hazard in a domestic setting. For example, a horned milking doe who must have her head in a stanchion twice a day could get caught and hurt herself if she were startled during milking. Horns get caught in fences and can injure human handlers and pen mates. When only some goats have horns, those with horns have an advantage in competition for food and space over the disbudded goats.

An alternative method for horn removal is surgery, but it is an expensive procedure if you are running a commercial-scale dairy and it poses a much greater health risk to the goat. There are also caustic chemical pastes available for horn removal at an early age. These can be dangerous, as the paste can be rubbed accidentally into the eyes of the kid, or onto other kids, causing severe damage. For these reasons, we will focus on disbudding with an electric iron.

Disbudding, depending on goat breed and gender, could be needed as early as a few days of age, or whenever you can clearly feel the horn buds. Hair growth over the horn bud should be palpated (i.e., felt by hand) so you can avoid trying to disbud a naturally polled (i.e., hornless-which is generally rare) kid. The hair on the horn bud will grow in a swirl over the horn bud, whereas the hair on a polled kid will grow flat over the horn area. Most importantly, you will need an effective way to restrain the kid during the process. Remember, you are working with a hot iron and any movement by the kid will create a greater hazard to you, the kid, and anyone else who is helping you. The common restraint tool is a kid disbudding box, available through livestock supply catalogs. This box completely encloses the kid, with the exception of the head, and allows one person to do the disbudding unassisted. Several brands of electric iron are available through most supply catalogs and their effectiveness does not vary to any great extent, although a hotter iron may be more desirable as it reduces disbudding time. Most sources recommend an iron with a $3 / 4-$ to 1 -inch diameter tip. Shaving the horn bud before you start will provide you with a better view of what you are doing and will also lessen the smell from burnt hair. 


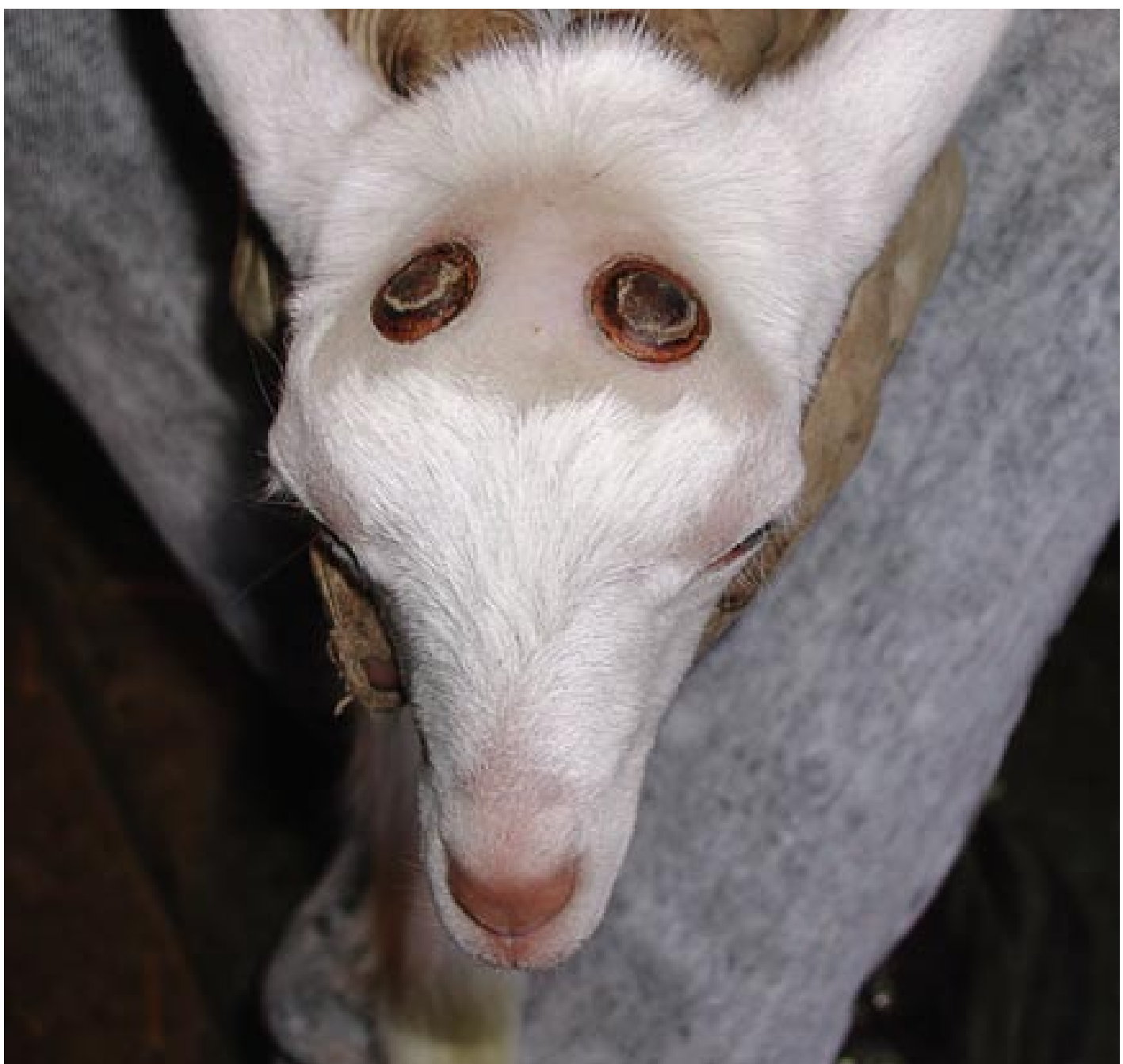

After application of the disbudding iron, but prior to removal of the horn bud caps. The outer ring, which should be no smaller, will be copper in color.

Breeders who have not already vaccinated their kids against tetanus will usually give each kid a preventative tetanus antitoxin injection prior to disbudding. Start burning when the tip of the iron is red-hot. How long you burn will depend on the strength of the iron and the size of the horn bud. Weaker irons may take as long as 20 seconds while stronger irons may take as little as 6 seconds. The only consistent rule of thumb is that you must apply the iron until you see a dry, copper-colored ring around the horn bud. You can also flip the tip off of the horn bud with the iron as it weakens as you burn around it.

After disbudding, apply medication as recommended by your veterinarian to cool the area and protect it from infection. The best approach for an inexperienced person is to get an experienced person to demonstrate it several times, taking care to feel the horn bud before burning and notice how the horn bud looks after disbudding. Of all horn-removal methods, disbudding is the least dangerous to the kid. Kids bounce back remarkably quickly, especially if fed a bottle of milk immediately after disbudding, and they will be playing normally soon after the procedure.

\section{IDENTIFICATION SYSTEMS}

Most dairy goat producers find thorough record-keeping to be essential to a good management program. If you plan to keep records on your goats, you will need to give each goat some form of permanent individual identification. Tattooing is the most 
widely used identification system, and you can do it at the same time as disbudding. It is a permanent form of identification: if done correctly, the tattoo will last throughout the goat's life. It is also very convenient to simply look in the goat's ear (or under the tail for LaMancha goats, which have very short ears) for immediate identification. Microchipping is a newer possibility, but then you have to have a scanner on hand to identify the goat. Ear tags are also easy to see, but goats can rip them out and lose them.

An effort is currently underway to implement a mandatory nationwide system for permanent animal identification, but for now tattooing is probably the easiest and most reliable practice. Tattooing tools are readily available through livestock catalogs. You can find information on the American Dairy Goat Association's identification system as well as instructions on how to tattoo your kids online at the ADGA website, http://www.adga.org.

\section{HOOF TRIMMING}

Kids may need to have their hooves trimmed as early as two months of age. To determine when you need to start trimming, examine the hoof for long edges around the perimeter of the hoof or heel, either of which may fold inward. Keeping the hooves trimmed is a healthy practice and can prevent serious foot problems such as hoof rot and abscesses. The goat's foot bones can be thrown out of line, causing lameness, if the hooves are not properly cared for.

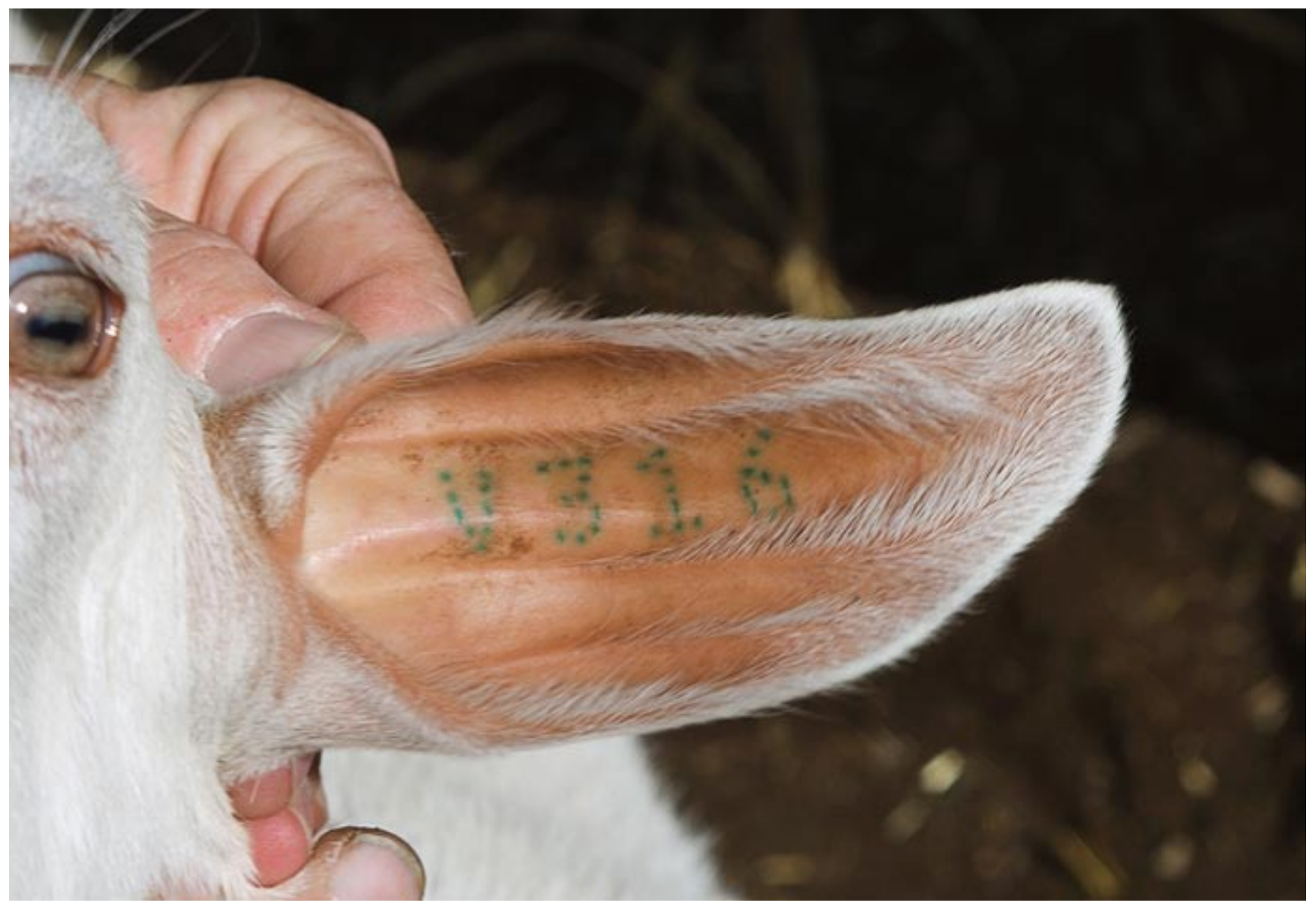

A well-done ear tattoo remains legible for the life of the goat. An illegible tattoo will create difficulties with herd records. 
Getting the kids used to hoof trimming early on will be helpful in the long run. Hoof trimming is a constant chore on a goat dairy. Hooves need to be checked monthly in all seasons as some goats' hooves may grow faster than others. In wetter months, hooves are easier to trim as the moisture softens the hoof. You can use pruning shears, a farrier's knife, or even a jackknife, but hoof trimmers with a straight cutting edge are strongly recommended to avoid injury to you or the goat. Using a stanchion or tying the goat's head to a rail to trim hooves are good ways to keep the goat still while minimizing stress. To trim the hooves, cut away any long edges that rise over the sole of the hoof. The goal is to obtain a flat, level surface for the goat to walk on. You can also smooth the surface with a hoof plane or rasp. Serious injuries to the goat are uncommon, but you may cause some bleeding if you cut the hoof too deeply. If this happens, apply a blood stop powder; if bleeding is profuse, you can apply a loose bandage with the powder to encase the hoof. This type of bandage must be applied with care: too loose a bandage may fall off immediately, but a bandage that is too tight can cut off circulation to the hoof. Seek veterinary assistance if you are unsure how to proceed.

\section{HOUSING: PRE- AND POST-WEANING}

A housing area that can be easily sterilized between kid groups is ideal. Kids are inquisitive and rambunctious at all times. If there is any possible way for them to get into trouble they will generally find it. Keeping this in mind, pay special attention to potential escape routes and hazardous materials in or near pens. The sharp end of a metal wire used to hold a panel in place can cause a deep gash in a kid. A small grain trough hanging on a fence could be just the right height to help an acrobatic kid leap the fence.

A well-graveled pen can help prevent standing water (goats are extremely unhappy if they cannot avoid standing in water), but a gravel surface can be difficult to clean and accumulated manure can provide a breeding area for flies. Gravel does, however, have the advantage of low cost and it breaks up animal waste by sifting the smaller pieces below the gravel surface. A sloped concrete area, although more expensive, is easy to clean and sterilize between kid groups. Whatever surface you keep the kids on, the pen should be monitored for cleanliness and cleaned on a regular basis. Otherwise, the accumulation of waste material creates an environment that allows the growth of bacteria, including pathogenic species.

The kid pen should also include weatherproof shelter. Wet and chilled kids are much more susceptible to sicknesses, including pneumonia. Dry, draft-free housing that is adequate for the number of kids kept in the pen is essential. Larger kids will crowd smaller ones in a shelter and, in cases of severe overcrowding, they can smother their smaller pen mates. For this reason, it is often best to pen kids together based on age and size. It is nice if the houses are easy to move so you can prevent the accumulation of waste material inside them. Several producers in our survey felt that finding and maintaining adequate space to house kids was the hardest management challenge to overcome. While you can easily adjust such things as vaccination schedules and feed rations to meet the needs of the kids, space availability on a dairy usually is not so easy to manipulate if the kid population outgrows your original expectations.

Overcrowded kids create several management headaches for the producer. For example, competition for space at the feeder can hinder the growth of younger or smaller kids. Pen sanitation becomes harder to manage and, as a result, disease outbreaks become harder to control. Illnesses such as Cryptosporidiosis and scours (diarrhea) spread extremely quickly in an overcrowded pen and can cause devastating mortality and morbidity losses to the kid crop.

A simple basic rule is to keep only as many kids in the pen as there are spaces 
for them to eat. This is very important if you are using a lamb-bar type self-feeder (see photos, page 8). Kids who are constantly defeated when competing for feed will learn to wait for the other kids to finish. In some cases kids just stop trying altogether and wean themselves early, thereby compromising their growth potential.

In addition, make sure that all kids are able to take advantage of the shelter you have provided and are not either forced outside in inclement weather or forced to cram together to find space in the house. Be aware that goats do have a natural inclination to snuggle in small groups, though, which is not a sign of overcrowding. Of the dairies we surveyed, 5 out of the 6 grouped their kids by size or weight rather than by age, a method that ensures that smaller kids will be able to compete for feed and space.

\section{HEALTH PROGRAMS}

Every commercial goat herd should have a written preventive health program that has been prepared in consultation with a veterinarian to protect the animals from health problems. A healthy doe will have a higher activity level, a better appetite, and a stronger immune system. Healthy does also produce more milk since they can use their dietary energy for milk production rather than warding off disease.

Health programs vary greatly with differing management needs, so it is best to consult with a veterinarian in your area, preferably with specific experience in goats, as you draw up the program for your herd. For example, in California some areas are deficient in selenium and others are high in selenium, and you must take care to know the specifics for your area since goats can suffer if they have either an excess or a deficiency of selenium. When considering your options for feed supplementation, make sure to consult with your nutritionist or veterinarian.

Internal parasites can rob a kid of its full potential to grow and develop. Roundworm larvae can be ingested from infected pastures, reach maturity and lay eggs in about 2 to 6 weeks, then be passed back onto the pastures by infected goats to continue the cycle. Coccidiosis is caused by a protozoan that inhabits the intestinal tract. Kids stricken with coccidiosis can sustain permanent damage to the intestines that will prevent their full absorption of nutrients and make them unthrifty. You can analyze fecal samples to determine the type and degree of infestations. Preventive worming, coccidian treatments, and vaccinations are available for goats, but all should be used under the direction of a veterinarian.

Another example is tetanus. Horses are carriers for tetanus and can shed the disease, so if horses have been housed on the property within the last 20 years you may want to consider vaccinating your goats for tetanus. Kids without immunity to the disease can die at an early age if they contract tetanus. There are a number of other herd diseases and disorders that you can prevent by following a carefully developed herd health program.

Perhaps the biggest challenge to goat producers is CAE, and great emphasis should be placed on maintaining a CAE-free herd. CAE is a degenerative disease that is passed from infected does through milk or from doe to doe in body fluids or secretions. An event as common as one doe rubbing noses with another doe can transmit the disease if one of the does is already infected. CAE creates physical ailments, such as arthritis, that can limit mobility. It can also create other problems, including neurological symptoms that can result in premature death. The most devastating thing about this disease is that there is no cure. The only way to avoid problems associated with CAE is to maintain a CAE-free herd. Take precautions to obtain your goats from CAE-free herds, or at a minimum identify CAE-positive goats and keep them separate from the rest of the herd. Kids must be 6 months old before they can be tested. A blood sample is taken, usually from the neck. If you take care to eradicate CAE from 
your herd and then to maintain the herd at that status, you will greatly reduce overall mortality and morbidity in the long run.

Some producers promote a "closed herd" - that is, they make it a practice never to introduce new goats into an established herd, thus limiting the introduction of disease. A producer who follows this practice can avoid some costs of vaccinations (but not all costs, since the practice of not vaccinating is not widely recommended), but the practice does have its problems. For example, a closed herd without a vaccination program is susceptible to cases of tetanus and Clostridia infections. The health program of a closed herd must also address the possibility that people who visit the operation may carry pathogens into the herd. A closed-herd program also hinders the addition of new genetics into the herd except by artificial insemination, which can be costly and have a low success rate.

The best thing that you can do as a new producer is to contact other producers in your area about local herd health issues. Find out what diseases their herds have encountered. Then consult a veterinarian to work out a specific health program for your own herd.

\section{SOLID FEEDS AND WEANING}

There are many post-weaning diets to choose from that will work well for kids. You must follow some basic rules, however, when deciding what to feed them. The first rule is that the kids have to be willing to eat it. The cartoon goat who eats tin cans seems to characterize the common notion of a goat diet. In reality, though, goats are browsers and are actually more finicky about what they eat than most other species, certainly more so than cattle.

For a commercial-scale operation it would be unrealistic and costly to attempt to buy hay or grain in small lots in order to determine its intake potential or palatability. To avoid waste from "sorting" (when the goats eat the leaves and waste the stems), most producers feed primarily dairy-quality alfalfa. Dairy-quality is the term used to describe the highest-quality grades of alfalfa. High-quality alfalfa is an essential feed for a goat herd as goats will not eat large stems unless forced to, so using a lowergrade alfalfa would result in high wastage of feed. A bale of higher-quality alfalfa costs more, but it will be more economical in the long term as a much higher proportion of it will be eaten.

Even the feeder itself can cause a waste of feed. A goat's natural tendency to browse and look up to find food gives it the urge to jump and climb. At the same time, goats are less likely to eat hay or grain after they have had their dirty hooves in it. Thus, a feeder with a trough in the bottom to catch the alfalfa leaves is beneficial, although the ideal feeder would also discourage kids from putting their feet in the trough. One way to accomplish this is to use a wooden board with a hole only large enough for the kids to stick their head through. This can work well, but the wooden barrier can be difficult to keep dry, can harbor bacteria, and is space limiting. As an alternative, you can have two metal panels spaced far enough apart to allow room for hay in between, and 6-X-8-inch rectangular mesh that allows kids to put their head through without getting stuck over a trough (preferably plastic or metal and about 12 to 18 inches high) to keep the hay or leaves from falling to the ground. Keep in mind that this design will not work for horned goats. If you do not want to make your own feeders, many designs are available from livestock catalogs. Keep in mind, though, that with kids, no system is perfect. It may be best to talk with other goat producers about what system will work best for you.

At the UC Davis Dairy Goat Facility, workers have noted that curious kids will start nibbling alfalfa before they show interest in grain, so beginning at about 14 days 


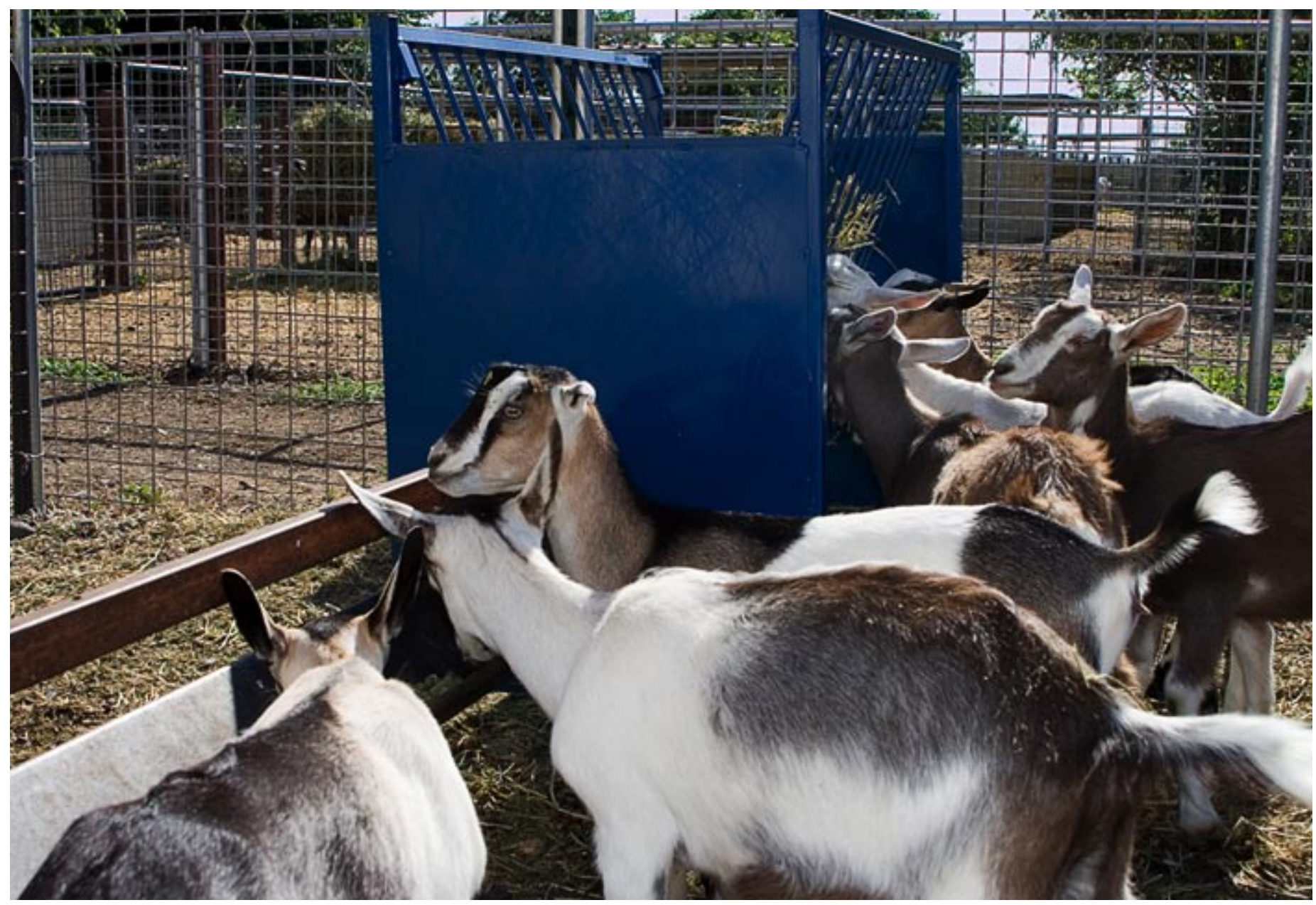

Kids using a hay rack (center) and a grain trough (left) at the UC Davis goat barn.

of age kids are offered small amounts of alfalfa. All producers in our survey offered their kids a grain-based concentrate along with hay or pasture. This is good for the kids, as a concentrate feed provides the added energy needed for the rapid growth that is a characteristic of this stage in the kids' lives. It also provides a balanced plane of nutrition at a stressful time in the kids' lives as they change from a liquid to solid diet.

Occasionally, kids will not continue to eat solid feed at acceptable levels right after weaning. The removal of liquid feed negatively impacts their overall intake, with the result of a loss of body weight and condition. Studies have found that pre-weaning feeding kids with some concentrate, as well as hay, is the best way to stimulate rumen development so that they will be able to digest these feeds most effectively when they transition completely to solid feeds. This is the recommended way to wean kids, as it minimizes the stress from changing diets and prepares the digestive system for digesting solid feeds. At the UC Davis Goat Facility, small amounts of a mixed grain concentrate are offered at about 28 days of age, and weaning occurs at 90 days.

Concentrates can be in loose or pellet forms. Some producers favor the pellets because they are uniform and make it easier to prevent waste from the kids sorting out less desirable components. By feeding twice a day and only providing as much feed as the kids will eat in a few minutes, you can pretty well eliminate sorting. Pelleted feeds are not perfect, though: they can still be wasted since kids will not always eat the fines (the smaller particles left at the bottom of the trough). Pellets, if they include forage, do have the advantage that you can provide them more liberally, 
with less concern about over-consumption so long as the pellets' concentrate-to-alfalfa ratio is relatively low.

Feeding newly weaned kids too much grain can cause indigestion and scours, which can be fatal in chronic or severe cases. Excessive intake of concentrates will reduce the $\mathrm{pH}$ in the rumen, causing acidosis, which can in turn sharply reduce feed intake. Always consult a professional animal nutritionist to determine exactly what diet will meet the needs of your kids and optimize kid growth. A nutrition professional is best able to formulate a least-cost ration that will meet your kids' nutritional needs and still take full advantage of the feeds that are available to you on-farm.

The criteria for weaning kids vary among goat producers: some wean by age and some by weight or body condition. In fact, most producers are likely to consider all three factors, although each may regard one as being more important than the others. For example, goat dairies that wean by age will probably hold back an individual kid that does not have enough body condition until it is able to catch up with the group. In contrast, heavy, faster-growing kids that fight off other kids seeking milk have the potential to become too heavily conditioned, and may get advanced into a weaned group at an earlier age. Kids that weigh the desired amount relative to your weaning protocol but are larger-framed and under-conditioned could, by the same token, be held back. Optimal weaning decisions require a knowledge of each kid's body weight and condition relationships. One experienced breeder gave us this description of her weaning protocol (keep in mind that this is only one person's opinion and that experiences vary by breed and specific conditions):

I wean by weight, not by age, and $30 \mathrm{lb}$ is the weight I look for (usually $2^{1 / 2}$ months for most of them). They are consuming probably 1 to $1 \frac{1 / 4}{1 b}$ of grain per day (divided into two feedings). I feed two times a day until they are $50 \mathrm{lb}$ (increasing grain appropriately) then I feed one time a day until they are about $70 \mathrm{lb}$ and ready to breed. I feed more of a challenge-type regimen where I feed them as much as they will clean up in 5 minutes or so. If they still seem hungry a few minutes after feeding, then I increase feed. If there is still feed a few hours later, or if they are wasting feed, then I back off on amount. This is the same as the way I feed their hay.

Once again, the best way to become proficient in this skill is to consult experienced producers so you will be able to identify those kids with the ideal body weight and condition.

\section{CONCLUSION}

Raising healthy dairy goat kids can be one of the most rewarding aspects of a commercial goat operation, a successful effort takes a lot of hard work. Besides the brief overview given here, a beginning dairy goat producer should seek out more detailed information from a variety of sources before purchasing goats or making management decisions.

The experiences of the six successful goat producers included in our survey, although not necessarily "best management practices," are reflected in their survey responses listed in the Appendix Table. These will give you an idea of how some commercial California goat dairies raise their kids.

Published information, although it exists in quantity on the internet, is often of a limited scope, sometimes misleading or incorrect, and often out of date. In your research, rely most on publications from recognized institutions and groups and on the views and practices of experienced producers where possible for your best road to success. 


\section{ACKNOWLEDGMENTS}

Special thanks to the dairies that participated in the survey, as well as to Jan Carlson, Bill Verboort, Dr. Joan Dean Rowe, Erika Scharfen, Dr. Caroline Stull, and the goats of the UC Davis Dairy Goat Facility for all of the information that they have all contributed in hope of improving the California dairy goat industry. Deborah Giraud (UC Cooperative Extension Farm Advisor in Humboldt County) initiated this project. A grant from California Food, Fibers, and Futures, a Kellogg Foundation Initiative, provided support funds for this project, as well as for a Dairy Goat Cost Study and a Kid Raising Feasibility Study (http://www.coststudies.ucdavis.edu).

\section{REFERENCES AND RESOURCES}

American Dairy Goat Association website.

http://www.adga.org.

Anonymous. 1999. Caprine supply's goatkeeping 101. 3rd Edition. DeSoto, KS: Caprine Supply.

Belanger, J. 2001. Storey's guide to raising dairy goats. Pownal, VT: Storey Communications Inc.

Collar, C., et al. 2000. Goat care practices, 1st ed. Davis: University of California, Davis. http://www.vetmed.ucdavis.edu/vetext/INF-GO.html

Considine, H., and G. W. Trimberger. 1978. Dairy goat judging techniques. Scottsdale, AZ: Dairy Goat Journal Publishing Corporation.

Heinrichs, A. J., and C. M. Jones. 2003. Feeding the newborn calf. State College, PA: Pennsylvania State University.

National Research Council. 1981. Nutrient requirements of goats. Washington, DC: National Academy of Sciences.

Smith, M. C., and D. M. Sherman. 1994. Goat medicine. New York: Lea \& Febiger.

Thedford, T. R. 1983. Goat health handbook. Morrilton, AR: Winrock International. 


\begin{tabular}{|c|c|c|c|c|c|}
\hline Dairy 1 & Dairy 2 & Dairy 3 & Dairy 4 & Dairy 5 & Dairy 6 \\
\hline 300 to 400 & 300 to 400 & 300 to 400 & 3000 & 3000 & 200 to 300 \\
\hline 200 to 300 & 200 to 300 & 200 & 1200 & 2000 & 150 \\
\hline 3 to 4 & 5 to 6 & 3 to 4 & 3 to 4 & 8 & 4 to 5 \\
\hline yes & no & yes & no & yes & no \\
\hline yes & no & yes & yes & no & no \\
\hline no & no & no & no & yes & no \\
\hline
\end{tabular}

On DHIA/DHIR

Rolling herd average (lb/yr)

30-day production

(lb/first-lactating goat)

Breeding season

Criteria for first breeding

Average age at first breeding

Number of replacement

kids per year

Largest number of
kids at any time
Time to care for kids
$\begin{aligned} & \text { Biggest management } \\ & \text { challenge }\end{aligned}$
Most successful area

Vaccinations

Number of feedings per day

Colostrum feeding

Milk treatment process

Milk source for kids

Milk feeding system

Weaning criteria

2.5

Feed for weaned kids

hay/concentrate

Kid groupings

$$
\begin{gathered}
\text { range pasture/ } \\
\text { concentrate }
\end{gathered}
$$

by age

by size/weight

by size/weight

do not move from normal pen

no

unknown

unknown

all year

body, weight, age

8 to 10 months

75 to 100

120

1 to $2 \mathrm{hr} /$ day
nutrition/disease
prevention

breeding program

Covexin-8, bose

2

first 2 to 3 days

pasteurize all milk fed

own herd/replacer

lamb-bar type

$30 \mathrm{lb}$

\section{range pasture/} concentrate

small group

large groups, then pens
3 people, $10 \mathrm{hr} /$ day

disease prevention

$\begin{array}{r}\text { yes } \\ 1800 \\ \hline 80\end{array}$

all year
body, weight

spring

summer, fall

no (extra cost)

no (extra cost/time)

unknown

unknown

unknown

unknown

6 to 7 months

400

8 months

body condition

10 to 12 months

\section{0}

700 to 1000

80

1500 (including market wethers)

\begin{tabular}{c|c}
\hline $6 \mathrm{hr} /$ day & $2 \mathrm{hr} / \mathrm{day}$ \\
\hline space & space \\
\hline
\end{tabular}

feeding program

housing

$$
\text { housing }
$$

CDT, mycoplasma

no vaccinations; antitoxin at disbud

\section{2}

2

$$
3
$$

first 2 feedings

first 3 feedings

first 2 days

heat-treat colostrum

no

raw milk only

replacer

replacer only

cow milk

bottle at first, then

lamb-bar (bottle for colostrum)

buckets lamb-bar

40 to 45 days'
age/20 to $25 \mathrm{lb}$

wean themselves

30 to $40 \mathrm{lb}$

hay/concentrate at 3 months, then pasture

hay/concentrate

hay/concentrate and/or pasture/ concentrate

\section{by size/weight}

by size/body condition

by size/weight

do not move from normal pen small group

large group kidding pens 
Appendix Table. Kidding survey responses for six commercial dairy goat operators, (cont.)

\begin{tabular}{|c|c|c|c|c|c|c|}
\hline & Dairy 1 & Dairy 2 & Dairy 3 & Dairy 4 & Dairy 5 & Dairy 6 \\
\hline Housing for kids & pens in barn & sheds & $\begin{array}{l}\text { calf hutches/ } \\
\text { sheds/barn }\end{array}$ & pens in barn & bunkers $\left(4^{\prime} \times 8^{\prime}\right)$ & pens in barn \\
\hline Sell cull doe kids? & after colostrum & after colostrum & $\begin{array}{l}40 \text { to } 50 \mathrm{lb} \text { for } \\
\text { market }\end{array}$ & keeps all doe kids & keeps all doe kids & as soon as born \\
\hline Cost per replacement doe & $\$ 400$ to $\$ 500$ & $\$ 300$ & $\$ 120$ to $\$ 150$ & $\$ 200$ & $\$ 150$ & $\$ 300$ \\
\hline Most replacements from ... & own herd & own herd & own herd & wherever possible & $\begin{array}{l}\text { own herd only } \\
\text { (closed herd) }\end{array}$ & $\begin{array}{l}\text { own herd only } \\
\text { (closed herd) }\end{array}$ \\
\hline Commercial kid operation? & $\begin{array}{c}\text { no } \\
\text { (would consider) }\end{array}$ & $\begin{array}{c}\text { no } \\
\text { (would not consider) }\end{array}$ & $\begin{array}{c}\text { no } \\
\text { (would not consider) }\end{array}$ & $\begin{array}{c}\text { no } \\
\text { (currently seeking) }\end{array}$ & $\begin{array}{c}\text { no } \\
\text { (would not consider) }\end{array}$ & $\begin{array}{c}\text { no } \\
\text { (would not consider) }\end{array}$ \\
\hline
\end{tabular}

\section{FOR MORE INFORMATION}

You will find related information in these titles and in other publications, slide sets, CD-ROMs, and videos from UC ANR:

Goats for California Brushlands, Publication 21044

Nutrition and Feeding of Dairy Goats, Publication WREP14

Production Testing for Dairy Goats, Publication WREP40

Protecting Dairy Goats from Poisonous Plants, Publication WREP46

To order these products, visit our online catalog at http://anrcatalog.ucdavis.edu. You can also place orders by mail, phone, or FAX, or request a printed catalog of publications, slide sets, CD-ROMs, and videos from

University of California

Agriculture and Natural Resources

Communication Services

6701 San Pablo Avenue, 2nd Floor

Oakland, California 94608-1239

Telephone: (800) 994-8849 or (510) 642-2431

FAX: (510) 643-5470

E-mail inquiries: danrcs@ucdavis.edu

An electronic version of this publication is available on the ANR Communication Services

Web site at http://anrcatalog.ucdavis.edu.

Publication 8160

This publication has been anonymously peer reviewed for technical accuracy by University of California scientists and other qualified professionals. This review process was managed by the REVIEWED ANR Associate Editor for Animal, Avian, Aquaculture, and Veterinary Sciences.

(C)2005 by the Regents of the University of California

Division of Agriculture and Natural Resources.

All rights reserved.

To simplify information, trade names of products have been used. No endorsement of named products is intended, nor is criticism implied of similar products that are not mentioned. 
The University of California prohibits discrimination or harassment of any person on the basis of race, color, national origin, religion, sex, gender identity, pregnancy (including childbirth, and medical conditions related to pregnancy or childbirth), physical or mental disability, medical condition (cancer-related or genetic characteristics), ancestry, marital status, age, sexual orientation, citizenship, or status as a covered veteran (covered veterans are special disabled veterans, recently separated veterans, Vietnam era veterans, or any other veterans who served on active duty during a war or in a campaign or expedition for which a campaign badge has been authorized) in any of its programs or activities.

University policy is intended to be consistent with the provisions of applicable State and Federal laws.

Inquiries regarding the University's nondiscrimination policies may be directed to the Affirmative Action/Staff Personnel Services Director, University of California, Agriculture and Natural Resources, 300 Lakeside Drive, $6^{\text {th }}$ Floor, Oakland, CA 94612-3550, (510) 987-0096. For information about obtaining this publication, call (800) 994-8849. For downloading information, call (530) 297-4445. 